\title{
HISTORIA DEL CANTÓN DE GOLFITO, COSTA RICA AÑOS 1864-2011
}

\section{HISTORY OF GOLFITO, COSTA RICA \\ 1864-2011}

\section{Edgardo Fonseca Zúñiga*}

\author{
RESUMEN
}

Este artículo detalla el desarrollo histórico del cantón de Golfito. En el primer apartado, se analizó el origen del cantón y las primeras actividades económicas y sociales realizadas en el Golfo Dulce. En un segundo punto, se estudió la influencia de la actividad bananera y en un tercer apartado, se investigó la situación del cantón después de la salida de la Compañía Bananera. Para lograr estos objetivos se realizó un análisis de la composición de la población a través de los censos desde el año 1864 hasta el 2011.

PALABRAS CLAVE: COSTA RICA * HISTORIA NACIONAL * ECONOMÍA AGRARIA * HISTORIA SOCIAL * MIGRACIÓN

\section{ABSTRACT}

This article details the historical development of the Canton of Golfito. First, the canton's origin and the economic and social activities carried out in Golfo Dulce were analyzed; then, the influence of the banana activity was studied and, finally, the situation of the canton after the departure of the Bananera Company was investigated. In order to achieve these objectives, an analisis of the given members of the population from 1864 to 2011 was performed.

KEYWORDS: COSTA RICA * NATIONAL HISTORY * AGRICULTURAL ECONOMICS * SOCIAL HISTORY * MIGRATION

1 Este artículo expone las principales conclusiones del capítulo de la tesis en Licenciatura en Historia de la Universidad de Costa Rica "Regionalización de la Educación Superior en Costa Rica, el caso del Recinto de Golfito de la Universidad de Costa Rica, 1984-2018".

* Recinto de Golfito de la Universidad de Costa Rica, Costa Rica.

edgardo.fonseca@ucr.ac.cr 


\section{INTRODUCCIÓN}

Este artículo pretende brindar una visión en conjunto del desarrollo histórico del cantón de Golfito desde la segunda mitad del siglo XIX hasta el presente. Para lograr este objetivo, la investigación fue dividida en tres partes. En un primer apartado, se analizó la dinámica social y administrativa de la región del Golfo Dulce, centro geográfico de Golfito, desde la segunda mitad del siglo XIX hasta 1949, cuando se da la fundación del cantón. En un segundo apartado, se analizó la dinámica socioeconómica y administrativa en este cantón durante el desarrollo del modelo capitalista y la producción de la Compañía Bananera de Costa Rica, desde la década de 1940 hasta 1984, año en el cual se da el finiquito de esta actividad. Finalmente, en una tercera parte, se estudió la nueva dinámica social y económica del cantón una vez que se abandonó la producción bananera, desde 1984 hasta el presente.

La fuente principal del estudio son los Censos de la República de Costa Rica desde el año 1864 hasta el 2011. En la medida de lo posible, en todas las secciones se analizaron datos relacionados con la composición de la población por sexos, grupos de edad, saldos migratorios, grupos étnicos y nacionalidad. Además de elementos económicos (oficios y trabajos), así como factores educativos (porcentajes de alfabetización y niveles de instrucción).

\section{LOS ORÍGENES: ENTRE GOLFO DULCE Y GOLFITO, 1864-1949}

En la época republicana se tiene conocimiento de poblamiento en la zona del Golfo Dulce hacia 1848 y hasta finales del siglo XIX, el cual involucra principalmente dos corrientes: los chiricanos, provenientes del actual Panamá y pobladores costarricenses de la Meseta Central, quienes estaban en búsqueda de nuevas tierras para el cultivo de granos y la producción ganadera (Royo, 2004). La dinámica poblacional del siglo XIX y las primeras décadas del siglo xx se resume en la tabla 1.
TABLA 1

POBLACIÓN TOTAL EN EL DISTRITO DE GOLFO 1864, 1883, 1892, 1904, 1916 Y 1927

\begin{tabular}{l|cc|c}
\hline \multirow{2}{*}{ AÑO } & \multicolumn{3}{|c}{ POBLACIÓN } \\
\cline { 2 - 4 } & HOMBRE & MUJER & TOTAL \\
\hline $1864^{1}$ & 464 & 467 & 931 \\
$1883^{2}$ & - & - & 392 \\
1892 & 303 & 220 & 523 \\
1904 & - & - & 681 \\
1916 & - & - & 808 \\
1927 & - & - & 1195 \\
\hline
\end{tabular}

Notas: ${ }^{1}$ Esta cifra incluye población de Boruca, Térraba y Golfo Dulce. Alejandra Boza calcula para la región de Golfo Dulce un total de 287 personas. La autora señala el método que utilizó para calcular esta población restándola del total presentado para Térraba y Boruca en otras fuentes. ${ }^{2}$ Según señala la misma autora, esta estimación y las de 1904 y 1916, son realizadas por el Departamento Nacional de Estadística basados en los nacimientos y defunciones registrados, además de las migraciones reportadas.

Fuente: República de Costa Rica, 1864; Dirección General de Estadística, 1892; Dirección General de Estadística y Censos, 1927; Boza, 2014. (Cuadro 1, p. 59, Cuadro 2, p. 68, Cuadro 3, p. 69, Cuadro 5 y Cuadro 6, p. 72).

Como se observa en la tabla 1, las autoridades nacionales tenían un conocimiento e inventario de población alrededor del Golfo Dulce desde la aplicación del primer censo en 1864 y hasta la segunda década del siglo xx, antes del inicio de la actividad bananera, con lo cual, aunque la población era poca y dispersa, esta fue una zona poblada desde los inicios de la república. Esta aumenta en el periodo en estudio y para el año 1927, después de varios intentos de colonización desde el centro del país, alcanza más de 1000 personas. La composición de la población del distrito de Golfo Dulce para 1864 se detalla en su distribución por grupos de edades en la tabla 2 y por nacionalidades en la tabla 3. 
TABLA 2

DISTRIBUCIÓN TOTAL Y PORCENTUAL DE LA POBLACIÓN DEL DISTRITO DE GOLFO DULCE POR GRUPOS DE EDADES

1864

\begin{tabular}{|c|c|c|c|c|c|c|}
\hline \multirow{2}{*}{ EDAD } & \multicolumn{2}{|c|}{ HOMBRE } & \multicolumn{2}{|c|}{ MUJER } & \multicolumn{2}{|c|}{ TOTAL } \\
\hline & & $\%$ & & $\%$ & & $\%$ \\
\hline Menos 15 años & 184 & 19,8 & 162 & 17,4 & 346 & 37,2 \\
\hline $15-30$ & 148 & 15,9 & 156 & 16,7 & 304 & 32,6 \\
\hline $30-45$ & 86 & 9,2 & 85 & 9,1 & 171 & 18,4 \\
\hline $45-60$ & 32 & 3,4 & 42 & 4,5 & 74 & 7,9 \\
\hline Más de 60 años & 14 & 1,5 & 22 & 2,4 & 36 & 3,9 \\
\hline TOTAL & 464 & 49,8 & 467 & 50,2 & 931 & 100,0 \\
\hline
\end{tabular}

Fuente: República de Costa Rica, 1864 (Cuadro VIII. A, Cuadro XII).

TABLA 3

DISTRIBUCIÓN TOTAL Y PORCENTUAL DE LA POBLACIÓN DEL DISTRITO DE GOLFO DULCE POR NACIONALIDAD

1864

\begin{tabular}{c|cc}
\hline \multirow{2}{*}{ NACIONALIDAD } & \multicolumn{2}{|c}{ TOTAL } \\
\cline { 2 - 3 } & \multicolumn{2}{|}{$\%$} \\
\hline Honduras & 1 & 0,1 \\
México & 1 & 0,1 \\
Colombia & 224 & 24,1 \\
Portugal & 4 & 0,4 \\
Alemania & 2 & 0,2 \\
Extranjeros nacidos en el país & 30 & 3,2 \\
Nacionales & 669 & 71,8 \\
\hline TOTAL & 931 & 100,0 \\
\hline
\end{tabular}

Fuente: República de Costa Rica, 1864 (Cuadro viII. A, Cuadro XII).

Un análisis de los datos de las tablas $2 y$ 3 muestra la paridad entre hombres y mujeres. Por edades, el mayor peso está en la población joven, pues las personas menores de 30 años son casi el $70 \%$ de la población total. Esto puede dar algunas pistas sobre el modelo económico que se va a desarrollar en esta zona durante el siglo XIX, al ser una zona de atracción de colonos y agricultores en busca de tierras, quienes generalmente se desplazan en edades productivas $y$ en grupos familiares. En lo referente a nacionalidades, se destaca la presencia de colombianos, con casi un cuarto de la población del distrito. Estos se presume vienen de Chiriquí y en general de Panamá, en ese momento provincia colombiana.

De esta manera, los chiricanos llegaron a colonizar importantes zonas cercanas al Golfo Dulce, la Península de Osa y Punta Burica, presionados por el cambio de la dinámica económica en Chiriquí con la expansión de las fincas ganaderas y el aumento de la población (Boza, 2014). Así, en el año de 1848, un chiricano fundó el caserío de Puntarenitas con 88 personas, el cual posteriormente fue conocido como Santo Domingo. Dicho centro urbano es trasladado y rebautizada como Puerto Jiménez en 1917 (Barrantes, 2005).

Entre 1849-1850, el gobierno de Costa Rica establece una jurisdicción sobre esta zona con la creación de la Jefatura Política del Golfo Dulce y ejecuta un proyecto de colonización de la península de Osa con familias francesas, ubicando a 7 de estas en 1851. (Barrantes, 2005).

Para el año de 1914, según la ley nro. 31, se funda el cantón de Osa con su cabecera en el asentamiento de Buenos Aires (Arias, agosto de 2007-febrero de 2008). Para el caso del actual Golfito, su territorio se contabilizó como el distrito número 5, nombrado Santo Domingo de Golfo Dulce. En 1929, según el decreto nro. 48, se crea la Segunda Alcaldía del cantón con sede en Puerto Jiménez y jurisdicción en Golfito (Arias, agosto de 2007-febrero de 2008). Para el año 1931, los vecinos del Golfo Dulce y Coto 
solicitaban ser segregados de Osa y agregados al cantón central de Puntarenas, pues aseguraban que la comunicación era más fluida con esta ciudad por los servicios de cabotaje.

En 1923, durante la construcción de la carretera Dominical-General, se realiza un informe sobre la situación de las distintas regiones de la Zona Sur. En el caso del Puerto Jiménez y Golfo Dulce, se asegura que la zona está poblada por un $80 \%$ de chiricanos (Arias, agosto de 2007-febrero de 2008). Esta tendencia migratoria de personas panameñas se mantiene y las autoridades gubernamentales redactan un informe titulado "Medios que se valen algunos panameños para acaparar tierras en la zona sur" en donde se detallan las actividades de esta población, relacionadas principalmente con el tráfico de ganado (Arias, agosto de 2007-febrero de 2008).

Por estos motivos y ante la premura de volver a tomar el control de este espacio, en el año de 1923 se promulga el decreto nro. 13, el cual autorizaba a todo costarricense mayor de 18 años que se estableciera en el cantón de Osa a obtener un baldío de 50 hectáreas. Principalmente, estas denuncias fueron presentadas por personas de Esparta, Puntarenas, San José y Alajuela.

Además, los resultados del informe redactado por Mariano Montealegre en 1930 describen a Puerto Jiménez como un asentamiento poblado de chiricanos, la mayoría agricultores (Arias, agosto de 2007-febrero de 2008). Se recomienda la segregación del Golfo Dulce del resto del cantón y su fundación como una zona administrativa independiente, además de volver a "nacionalizar" el territorio para combatir la presencia de la población panameña.

\section{MODELO CAPITALISTA Y PRODUCCIÓN \\ BANANERA EN GOLFITO, AÑOS 1949-1984}

Desde 1935, la United Fruit Company (UFCo) adquirió tierras en el Pacífico Central y Sur; por lo que en 1938, es firmado el contrato final entre la Compañía y el gobierno. Cabe destacar la opción que se da a la UFCo, en el Punto 4 Artículo 2, de construir un muelle de embarque $y$ un centro urbano en cualquier punto del Golfo Dulce que considere apto. El lugar finalmente escogido es el sitio exactamente ubicado al frente de Puerto Jiménez y de esta manera se funda Golfito como una ciudad-puerto, en concordancia con la estrategia portuaria de esta empresa transnacional (Contreras, 1974).

Por la ley nro.133 del año de 1938, se autoriza a Golfito como puerto de la nación y el muelle embarcó su primera carga de fruta en 1941. En un espacio de tiempo de una década, entre 1938 y 1948, utilizando a Golfito como eje central, se construyó en esta división un total de 246 kilómetros de línea férrea, una zona de embarque $y$ desembarque para manipular 4000 racimos por hora $y$ una ciudad para albergar a 7000 personas (Jones y Morrison, 1952).

La segregación de la zona del Golfo Dulce del extenso cantón de Osa se da por el decreto-ley de la Junta de Gobierno nro. 532 de junio de 1949, con lo cual la zona alrededor del golfo, con parte de la península y la zona fronteriza con Panamá, se concretan como un cantón independiente, el número 7 de la provincia de Puntarenas. A través de los años se darán nuevas segregaciones que irán disminuyendo el territorio de este nuevo cantón. Así, el censo de 1950 reporta tres distritos: Golfito, Puerto Jiménez y La Cuesta. En 1965 y en 1973, se crean los nuevos cantones de Coto Brus y Corredores, respectivamente. Golfito, después de estas disecciones en su territorio, contará con tres distritos: Golfito, Jiménez y Guaycará (creado en 1971) hasta la creación del distrito de Pavón, con lo cual se completa la división administrativa actual.

Además del espacio geográfico, la demografía del cantón se vio sumamente afectada por el inicio de la actividad bananera. Esto se observa en la evolución de la población testimoniada en los datos de los censos nacionales, los cuales se detallan en la tabla 4. 
TABLA 4

DISTRIBUCIÓN TOTAL Y PORCENTUAL DE LA POBLACIÓN POR SEXO Y DISTRITO

GOLFITO, 1940, 1950, 1963, 1973, 1984, 2000 Y 2011

\begin{tabular}{|c|c|c|c|c|c|c|c|}
\hline \multirow[t]{2}{*}{ AÑO } & DISTRITO & \multicolumn{2}{|c|}{ HOMBRES } & \multicolumn{2}{|c|}{ MUJERES } & \multicolumn{2}{|c|}{ TOTAL } \\
\hline & & & $\%$ & & $\%$ & & $\%$ \\
\hline 1940 & Golfito $^{1}$ & - & - & - & - & 1584 & 100,0 \\
\hline \multirow{3}{*}{1950} & Golfito $^{2}$ & & & & & 6062 & 58,3 \\
\hline & Jiménez & & & & & 1173 & 11,3 \\
\hline & La Cuesta $^{3}$ & & & & & 3161 & 30,4 \\
\hline TOTAL & & 6068 & 58,4 & 4328 & 41,6 & 10396 & 100,0 \\
\hline \multirow{3}{*}{1963} & Golfito & & & & & 17923 & 49,0 \\
\hline & Jiménez & & & & & 1578 & 4,3 \\
\hline & La Cuesta & & & & & 17066 & 46,7 \\
\hline TOTAL & & 20220 & 55,3 & 16347 & 44,7 & 36567 & 100,0 \\
\hline \multirow{5}{*}{1973} & Golfito & & & & & 13611 & 32,3 \\
\hline & Jiménez & & & & & 2231 & 5,3 \\
\hline & La Cuesta & & & & & 5195 & 12,3 \\
\hline & Corredores & & & & & 14452 & 33,4 \\
\hline & Guaycará & & & & & 7021 & 16,7 \\
\hline TOTAL & & 22328 & 52,7 & 20128 & 47,3 & 42510 & 100,0 \\
\hline \multirow{3}{*}{1984} & Golfito & & & & & 14937 & 51,5 \\
\hline & Jiménez & & & & & 4766 & 16,2 \\
\hline & Guaycará & & & & & 9340 & 32,3 \\
\hline TOTAL & & 15260 & 52,5 & 13783 & 47,5 & 29043 & 100,0 \\
\hline \multirow{3}{*}{2000} & Golfito & & & & & 10915 & 32,3 \\
\hline & Jiménez & & & & & 6102 & 18,1 \\
\hline & Guaycará & & & & & 11456 & 49,6 \\
\hline TOTAL & & 17523 & 51,8 & 16300 & 48,2 & 33823 & 100,0 \\
\hline \multirow{4}{*}{2011} & Golfito & & & & & 11284 & 28,8 \\
\hline & Jiménez & & & & & 8789 & 22,4 \\
\hline & Guaycará & & & & & 12918 & 33,0 \\
\hline & Pavón & & & & & 6159 & 15,8 \\
\hline TOTAL & & 19619 & 50,1 & 19531 & 49,9 & 39150 & 100,0 \\
\hline
\end{tabular}

Notas: 1. Distrito del cantón de Osa. 2. El distrito de Golfito incluye Guaycará, dividido como nuevo distrito hasta 1971.

3. El distrito de La Cuesta incluye el actual cantón de Coto Brus, creado en 1965 y el cantón de Corredores, creado en 1973.

Fuente: Elaboración a partir de Hernández (1985) e Instituto Nacional de Estadística y Censos [INEc], $2000 ; 2011$. 
La tabla 4 muestra el aumento notorio de la población al instalarse el muelle $y$ al encontrarse en pleno funcionamiento la actividad bananera. En diez años, de 1940 a 1950, el aumento es sumamente significativo, casi 9 veces. Este aumento es igualmente alto entre 1950 y 1963, siendo de más del triple, con una tasa de crecimiento geométrico de 9,95, el más alto registrado en el país (Consejo Superior Universitario Centroamericano [CSUCA], 1978). Esto significó que entre 1927 y 1963, el peso de la población en el Pacífico Sur pasó de 10\% a 16\% del total nacional (Instituto de Investigaciones Económicas [IIE], 1974). Además, entre 1927 y 1973, la participación del Pacífico Sur en el total de la población de la provincia de Puntarenas creció notablemente de 15 a 63 por ciento (IIE, 1974), con lo cual la atracción de personas a Golfito, eje principal del desarrollo de esta región, fue muy significativo.

Si a esto se suma que la mayoría de la población es masculina, se puede concluir que la actividad de la Compañía Bananera fue un polo de atracción de mano de obra, principalmente de varones, que llegaban para emplearse en las actividades derivadas de la producción bananera. Esta desproporción va disminuyendo conforme avanza el tiempo y para el año 1973, la relación es alrededor de un $53 \%$ contra un $47 \%$.

En 1950, el principal núcleo poblacional es la ciudad puerto de Golfito y concentra a la mayor cantidad de población. Este porcentaje baja en los dos censos siguientes y la población se distribuye más equitativamente entre los distritos de Golfito (donde se ubica el puerto) y La Cuesta, fronterizo con Panamá y donde se ubican una gran cantidad de fincas bananeras. Entre 1950 y 1973, en el distrito de Jiménez, el porcentaje disminuye al pasar de $11,3 \%$ a $5,2 \%$. Esto evidencia la importancia que tomó la nueva ciudad-puerto y las zonas con las fincas de banano, lo cual deja como consecuencia la disminución del peso de la población de un asentamiento histórico en el Golfo Dulce como fue Puerto Jiménez.

Un análisis de la evolución de la población de Golfito por grupos de edad y la distribución por sexos puede aportar datos importantes para comprender cómo el asentamiento del modelo de producción bananero configuró a la población de este cantón (tabla 5).

TABLA 5

DISTRIBUCIÓN TOTAL Y PORCENTUAL DE LA POBLACIÓN POR SEXO Y GRUPO DE EDAD GOLFITO, 1950 Y 1963

\begin{tabular}{l|cc|c|c|cc|c|c}
\hline \multirow{2}{*}{ EDAD } & \multicolumn{4}{|c|}{1950} & \multicolumn{4}{c}{1963} \\
\cline { 2 - 8 } & $\mathrm{H}$ & $\mathrm{M}$ & TOTAL & $\%$ & $\mathrm{H}$ & $\mathrm{M}$ & TOTAL & $\%$ \\
\hline Menos de 1 & 208 & 181 & 389 & 3,7 & 786 & 727 & 1531 & 4,1 \\
$1-4$ & 626 & 582 & 582 & 11,6 & 2862 & 2779 & 5641 & 15,4 \\
$5-9$ & 564 & 546 & 1110 & 10,7 & 3036 & 2985 & 6021 & 16,5 \\
$10-19$ & 812 & 825 & 1637 & 15,7 & 3636 & 3463 & 7099 & 19,4 \\
$20-29$ & 1777 & 967 & 2744 & 26,4 & 3554 & 2347 & 5901 & 16,1 \\
$30-39$ & 1099 & 675 & 1774 & 17,1 & 2981 & 1840 & 4821 & 13,2 \\
$40-49$ & 581 & 305 & 886 & 8,5 & 1803 & 1157 & 2960 & 8,1 \\
$50-64$ & 333 & 202 & 535 & 5,1 & 1216 & 807 & 2023 & 5,5 \\
64 y más & 68 & 45 & 113 & 1,1 & 292 & 223 & 515 & 1,4 \\
Desconocido & - & - & - & - & 54 & 19 & 73 & 0,2 \\
\hline TOTAL & 6068 & 4328 & 10396 & 100,0 & 20220 & 16347 & 36567 & 100,0 \\
\hline
\end{tabular}

Fuente: Elaboración a partir de la Dirección General de Estadística y Censos (1950; 1963). 
La primera conclusión de la tabla 5 es el peso de la población con las edades más productivas, y entre ellos los más jóvenes, ubicados entre 20-29 años. En 1950, en plena consolidación de la actividad bananera, este grupo representó más de la cuarta parte de la población. Inclusive, las personas en este rango representaban el 26,4\% y el siguiente grupo, 30 a 39 años, representaba el 17,1\% del total de la población. Así, la importancia del porcentaje de los hombres en edad productiva en esta población indica la gran atracción que significó Golfito para este tipo de personas. En total, el grupo entre 20-39 años, representaba un poco más del 43\% del total.

Esta proporción baja en 1963 a 29,3\%, adquiriendo mayor importancia la población infantil, por ejemplo, el rango de 5-9 años aumenta en casi 6 puntos porcentuales. Esto puede sugerir la procreación de personas ya asentadas en el cantón. La población con mayor edad, de 40 años y más, prácticamente se mantiene equitativa porcentualmente en ambos periodos. En lo referente a la composición y distribución de la población golfiteña por zonas, en la tabla 6 se muestran los datos de acuerdo a los censos de 1950 y 1963.

TABLA 6

DISTRIBUCIÓN TOTAL Y PORCENTUAL DE LA POBLACIÓN POR SEXO, DISTRITO Y ZONA GOLFITO, 1950 Y 1963

\begin{tabular}{|c|c|c|c|c|c|c|c|c|}
\hline \multirow{2}{*}{ AÑO } & & \multirow{2}{*}{ \% POBLACIÓN } & \multicolumn{2}{|c|}{ GOLFITO } & \multicolumn{2}{|c|}{ JIMÉNEZ } & \multicolumn{2}{|c|}{ LA CUESTA } \\
\hline & & & $\mathrm{H}$ & M & $\mathrm{H}$ & M & $\mathrm{H}$ & M \\
\hline \multirow{2}{*}{1950} & Urbano & 40,9 & 2376 & 1880 & - & - & - & - \\
\hline & Rural & 59,1 & 1110 & 696 & 671 & 502 & 1911 & 1250 \\
\hline TOTAL & & 100,0 & 3486 & 4328 & 671 & 502 & 1911 & 1250 \\
\hline \multirow{2}{*}{1963} & Urbano & 18,7 & 3533 & 3326 & - & - & - & - \\
\hline & Rural & 81,3 & 6351 & 4731 & 865 & 713 & 9471 & 7595 \\
\hline TOTAL & & 100,0 & 9884 & 8039 & 865 & 713 & 9471 & 7595 \\
\hline
\end{tabular}

Fuente: Elaboración a partir de la Dirección General de Estadística y Censos (1950; 1963).

Se puede observar cómo el aumento de la población registrado entre ambos años significó un aumento en la población asentada en zona rural. En ambos años, la totalidad de la urbanidad se ubica en la ciudad-puerto de Golfito y, aun así, en este distrito, la población urbana cede ante la rural en 1963, disminuyendo más de la mitad. Este mismo año, muestra la importancia del distrito La Cuesta, el cual acumula la mayor cantidad de población rural y su población total es casi la misma que el distrito central de Golfito. Es en este distrito donde se ubica la mayor cantidad de fincas de banano, lo cual demuestra como la población del cantón se asentó en gran medida en este lugar para el desarrollo de estas actividades. La consolidación de la siembra de banano y la mayor demanda de trabajos como corta, deshierbe, fumigación, carga y todo lo referente al cultivo de la fruta, hizo que una importante cantidad de la población se asentara en las fincas, lo que dejó menos pobladores en el único centro urbano del cantón para este periodo, la ciudad de Golfito.

Otra característica de gran importancia en esta población es su condición migratoria y el lugar de origen de sus habitantes. Un análisis detallado de estos factores permite observar la composición de la población que fue atraída por la actividad bananera, las características de estas personas y las zonas de donde provienen, tanto del interior del país como del extranjero. En las tablas 7 y 8 se muestran los datos de los años 1963 y 1973. 
TABLA 7

DISTRIBUCIÓN TOTAL Y PORCENTUAL DE LA POBLACIÓN POR SEXO Y CONDICIÓN MIGRATORIA GOLFITO, 1963 Y 1973

\begin{tabular}{|c|c|c|c|c|c|c|c|c|c|c|c|c|}
\hline \multirow{3}{*}{ CONDICIÓN } & \multicolumn{6}{|c|}{1963} & \multicolumn{6}{|c|}{1973} \\
\hline & \multicolumn{2}{|c|}{ HOMBRES } & \multicolumn{2}{|c|}{ MUJERES } & \multicolumn{2}{|c|}{ TOTAL } & \multicolumn{2}{|c|}{ HOMBRES } & \multicolumn{2}{|c|}{ MUJERES } & \multicolumn{2}{|c|}{ TOTAL } \\
\hline & & $\%$ & & $\%$ & & $\%$ & & $\%$ & & $\%$ & & $\%$ \\
\hline Permanentes & 6734 & 18,4 & 6645 & 18,2 & 13199 & 36,1 & 17979 & 45,6 & 16354 & 38,4 & 34387 & 80,9 \\
\hline Inmigrantes $^{1}$ & 13486 & 36,9 & 9882 & 27,0 & 23368 & 63,9 & 4349 & 10,2 & 3774 & 8,9 & 8123 & 19,1 \\
\hline TOTAL & 20220 & 55,3 & 16347 & 44,7 & 36537 & 100,0 & 22328 & 52,5 & 20128 & 47,5 & 42510 & 100,0 \\
\hline
\end{tabular}

Nota: El cálculo de migración se realiza a partir de personas que reportan una residencia fuera de Golfito en los cinco años anteriores. El concepto Inmigrante incluye tanto a nacionales trasladados de otros cantones del país, como de llegados del extranjero.

Fuente: $\quad$ Elaboración a partir de la Dirección General de Estadística y Censos (1963; 1973)

El primer elemento a ser comparado es el porcentaje de residentes permanentes e inmigrantes. Para el año 1963, casi el 64\% de la población de Golfito había llegado a este cantón procedente de otro cantón nacional o fuera del país, con lo cual se evidencia que el aumento de la población en este cantón, registrado entre los censos de 1950 y 1963 , fue debido a la población migrante que llegó durante la consolidación de la producción bananera, con tasas de migración netas de $87,4 \%$ y $41 \%$ en ambos años censales (csucA, 1978). Este porcentaje disminuye significativamente diez años después y para el año de 1973, es alrededor del 20\%, con lo cual se evidencia un proceso de establecimiento en Golfito. Del total de inmigrantes en 1963, un $11,6 \%$ son extranjeros, la cifra baja a $9,6 \%$ para 1973, con lo cual, este cantón disminuyó su atractivo de migración extranjera. 


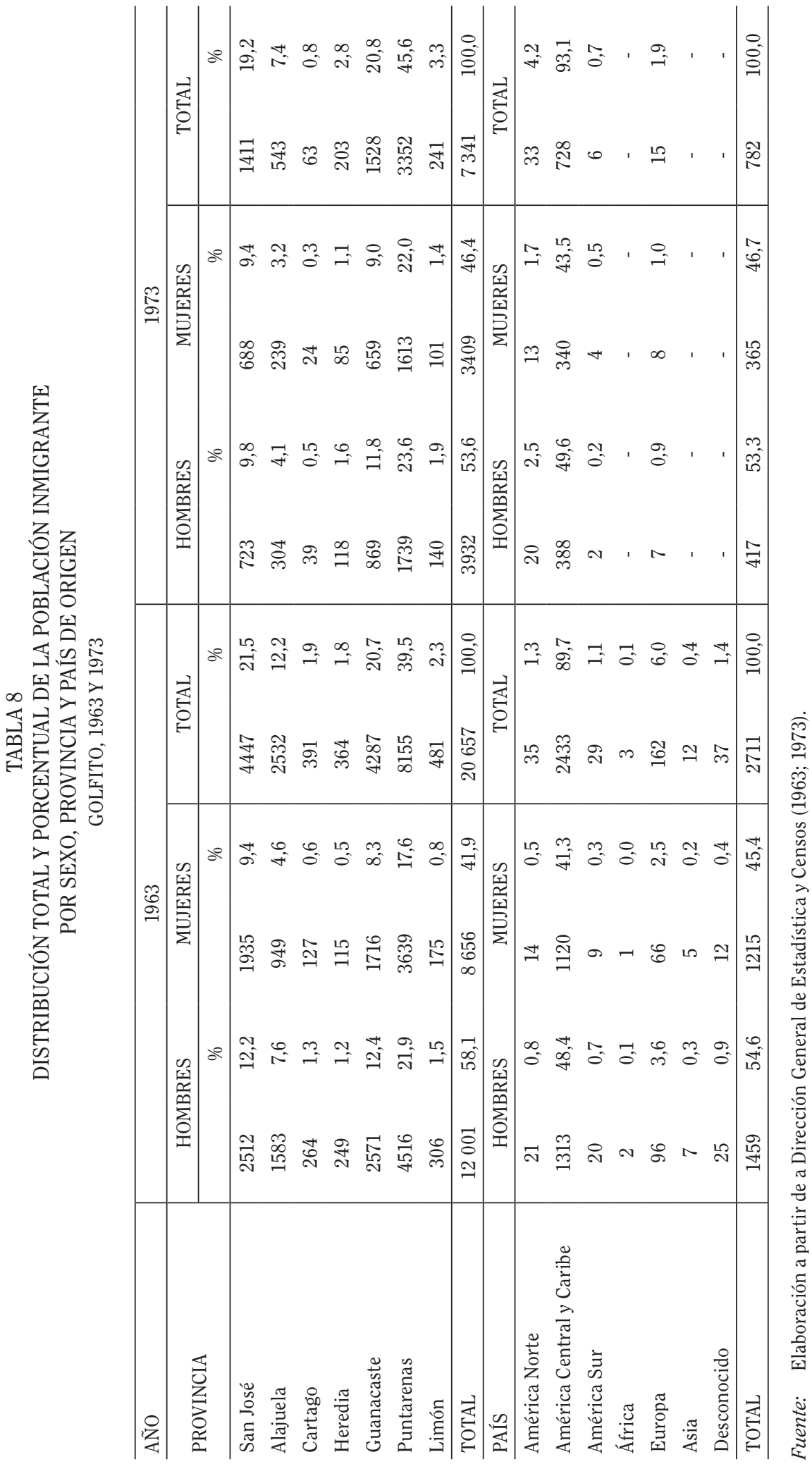


Como se observa en la tabla 8 , a nivel interno, en ambos casos, la mayoría de migrantes provienen de la provincia de Puntarenas. La diferencia es en el porcentaje, pues el 45,6\% del año 1973, contrastado con el 39,5\% del año 1963, indica que Golfito también dejó de ser un foco de atracción de migrantes del centro del país y atrajo a personas de su misma provincia. El Cantón Central de Puntarenas, Aguirre y Osa son los principales cantones de origen de estos migrantes. San José y Guanacaste son las otras dos provincias con mayor cantidad de personas migrantes. En el caso de San José, son el Cantón Central y Pérez Zeledón los que aporta más personas; en el caso de Guanacaste es el cantón de Nicoya.

A nivel internacional, el área de América Central y Caribe es la que reporta una mayor cantidad de personas, en ambos casos, con la presencia de panameños y nicaragüenses, en menor medida, de hondureños y salvadoreños. En el caso europeo, la mayor cantidad de personas proviene de Italia, con lo cual se recuerda que la colonización en San Vito de Coto Brus se contaba como parte de Golfito para el año 1963.
Para el año 1963, a nivel de sexo, gran parte de las personas migrantes son varones, debido a que el porcentaje de las poblaciones migrantes, interna y extranjera, poseen cifras superiores con respecto a los hombres. Entre estas dos poblaciones, el desequilibrio mayor se da en los migrantes internos con un $58,1 \%$ de hombres, en cambio, los extranjeros tienen una relación más pareja con un 54,6\%. En el año 1973, esa relación desigual se mantiene, aunque disminuye en ambas poblaciones. De esta manera, se puede inferir que la migración interna correspondió mayormente a hombres solos, mientras la extranjera pudo involucrar más parejas o grupos familiares.

Otro factor de gran importancia para caracterizar a la población de Golfito durante el periodo del apogeo de la producción bananera se refiere a sus particularidades escolares, grado de alfabetización y grado de instrucción. Un análisis detallado de la composición de población por su condición de alfabetización para el año 1950 se muestra en la tabla 9 . 


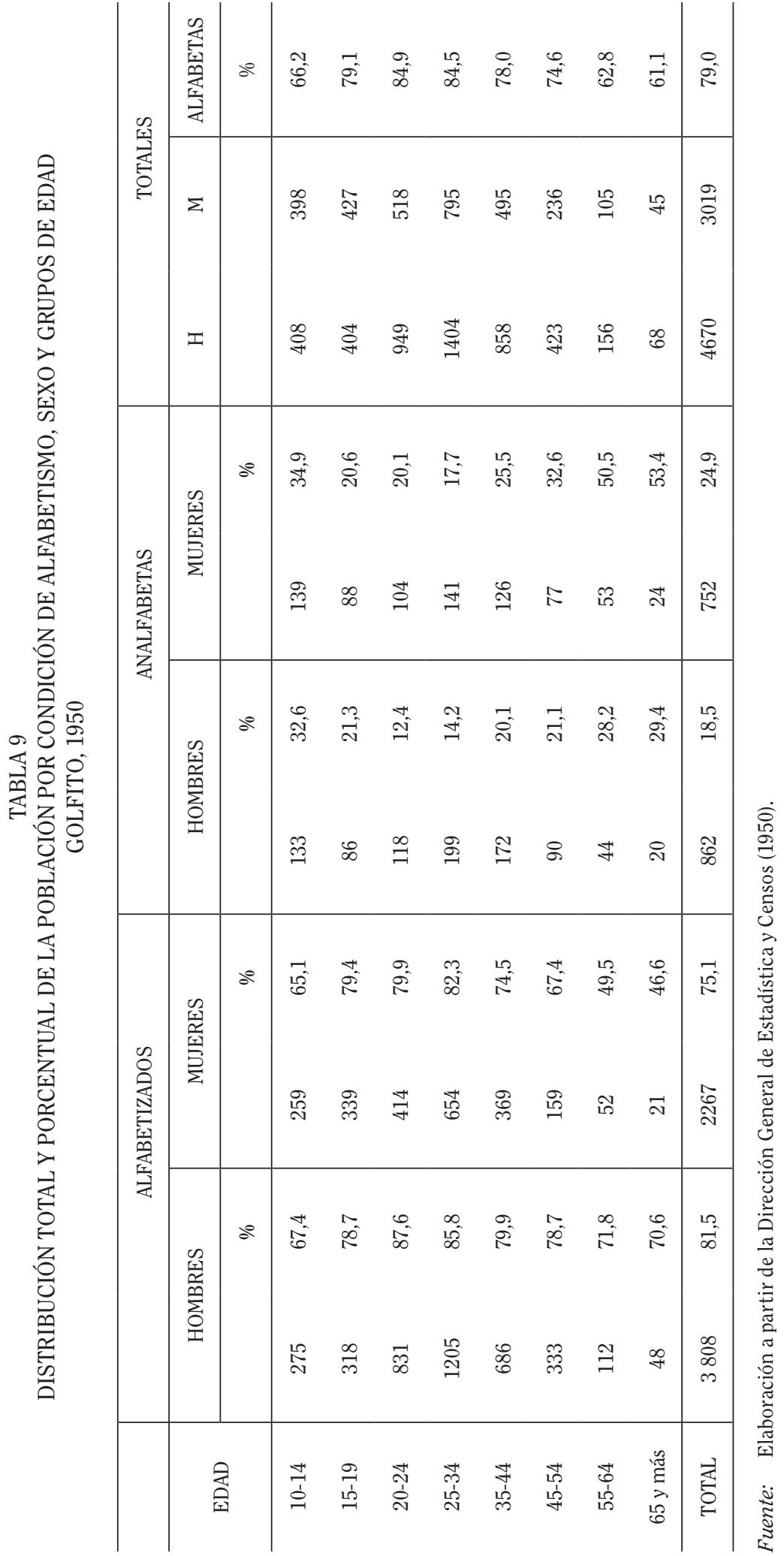


En general, en 1950, la alfabetización se ubica en $79 \%$. Al analizar esta condición por sexo, se obtiene que el $81,5 \%$ de los hombres se encuentran alfabetizados, mientras este nivel alcanza el $75,1 \%$ en las mujeres. De esta manera, se evidencia una diferencia significativa en ambos sexos, con mujeres más analfabetas; en ningún grupo las mujeres superan a los hombres, la diferencia más significativa es la registrada entre los 55 años y más, con poco más de la mitad de mujeres analfabetas en ese grupo. En general, después de 20 años, el alfabetismo disminuye conforme aumenta la edad, lo que evidencia la existencia de personas que no accedieron a educación en su edad escolar y no lograron completar su instrucción.

Por grupos de edades, los más alfabetizados son los ubicados entre 20 y 34 años, porcentaje mayor al de niños de 10 a 14 años, los cuales ya deberían haber completado los primeros años de instrucción. Esto puede sugerir que el nivel de alfabetización se obtiene ya en edades productivas, pues el alfabetismo sube al avanzar las primeras edades y nuevamente disminuye en los grupos de edades más avanzadas.

La Compañía tenía una enorme presencia en la administración de escuelas y la contratación de maestros, así en 1970 administraba 36 escuelas, empleaba a 190 personas para impartir clases y atendía a 5255 estudiantes (Abarca, 2005). Aun así, muchos obreros optaban por instruirse en su edad adulta y no en pocos casos con la ayuda de los sindicatos. La Compañía trabajó bajo tres divisiones: Quepos y Golfito en Costa Rica y Puerto Armuelles en Panamá. El cantón de Golfito se situó dentro de la llamada División Golfito, la cual concentró sus actividades desde la ribera sur del Térraba hasta la frontera panameña.

Hacia el año 1948, existían 3 distritos en la división con un cultivo de 25000 acres de bananos (Jones y Morrison, 1952). Estos distritos estaban subdivididos en intendencias las cuales supervisaban las fincas. Los nombres distritales fueron Palmar Sur, Esquinas y Los Cotos (Royo, 2004). Las fincas distribuidas en Palmar se contaban del 1 al 18, en Esquinas se encontraban 7 con los nombres de las provincias del país y en Los Cotos se contabilizaban las fincas del 41 al 65. Según Contreras (1974), un total de 26595 hectáreas de la tierra perteneciente a la Compañía se encontraban en Golfito para el año de 1974.

La división Golfito operó desde 1941 hasta 1984, la división Quepos operó hasta 1956 y en Laurel fue cesada la actividad bananera en 1973. Con esto la especialización de la división Golfito fue el banano. Los datos de los censos nacionales arrojan evidencia sustancial sobre la importancia de esta actividad económica en el cantón. De esta manera, en la tabla 10 se observa la distribución de las actividades económicas reportadas para los años de 1963 y 1973. 


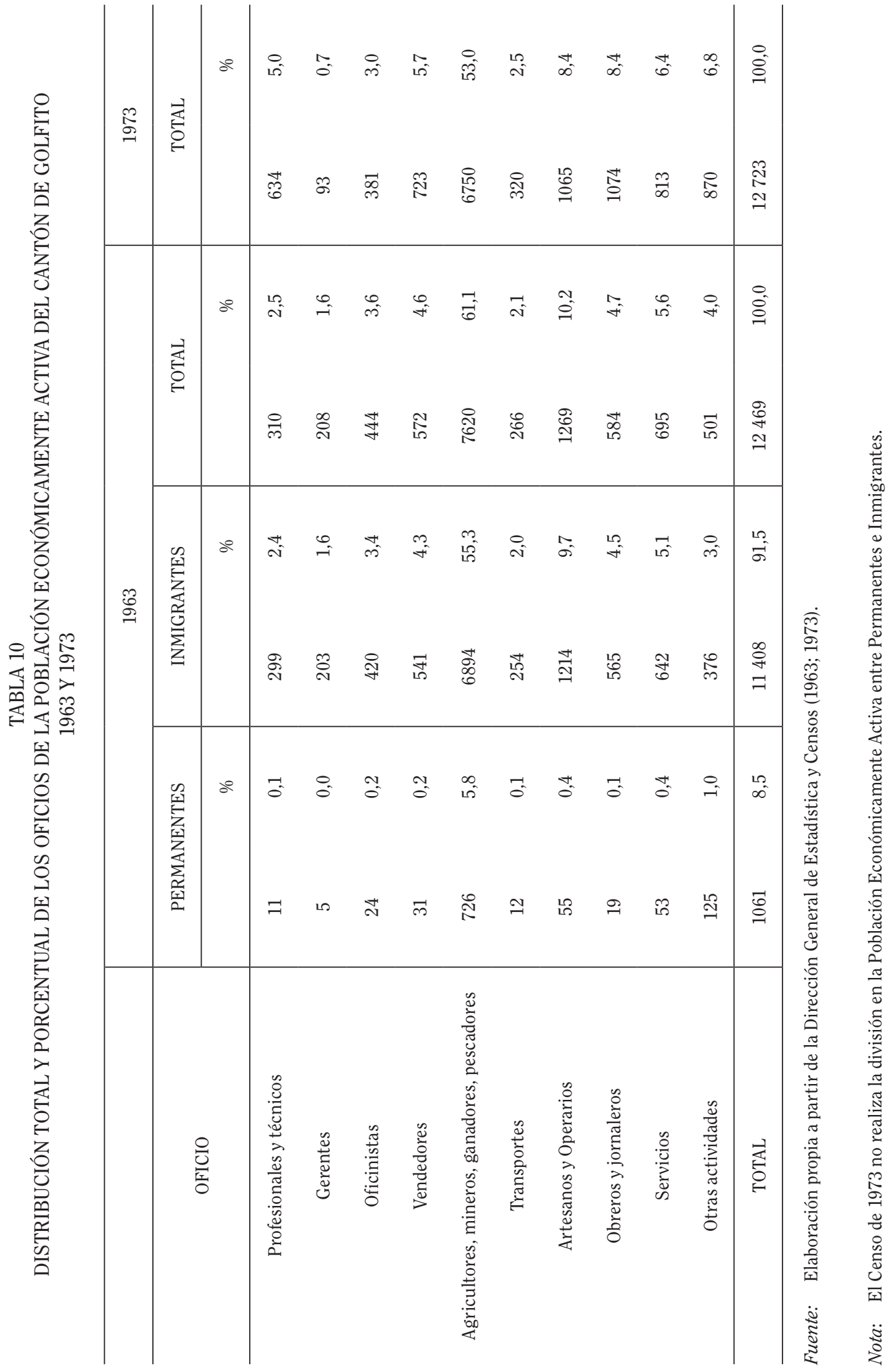


Lo primero a destacar es el peso del llamado grupo inmigrante en 1963. Estos son los pobladores que residían en un cantón o país distinto a Golfito durante los cinco años previos al censo. Así, la migración que atrajo Golfito fue de grupos económicamente activos, pues $91,5 \%$ de la fuerza laboral se encuentra en condición migrante.

En ambos años, la actividad que reúne a la mayor cantidad de trabajadores es la agrícola $y$, en general, la actividad agropecuaria. Aun así, el porcentaje de esta actividad baja de 1963 a 1973. Los artesanos y operarios también sufren una baja entre estos dos años censales, siendo los obreros y jornaleros una de las ramas que incrementó. La actividad de transportes, relacionada directamente con sacar la fruta de las fincas y la operación de los trenes, se mantiene estable en el periodo. Además, se reporta el aumento casi del doble en la rama profesional, con lo cual, la población de 1973, se traslada poco a poco a otras actividades económicas.

El modelo agrícola en el Pacífico Sur muestra que en 1909 únicamente 6,68\% de las hectáreas cultivadas eran utilizadas para la producción destinada a la exportación. Este dato cambia drásticamente hacia 1955, cuando el $60 \%$ de las hectáreas eran usadas en productos de exportación. Prácticamente, para esta fecha el $100 \%$ de la producción de banano exportable se concentraba en Osa y Golfito (Bartels y Araya, 2011).

\section{EL FINIQUITO DE LA COMPAÑÍA Y EL CESE DE LA ACTIVIDAD BANANERA, 1984-2011}

La situación económica y social de la Zona Sur se vio seriamente afectada con la decisión de la Compañía de adelantar el finiquito del contrato con el Estado, el cual debía expirar en 1988 y abandonar las operaciones en esta región cuatro años antes.

A nivel poblacional se debe recordar algunos de los datos mostrados en la tabla 4, en donde se observa la baja en el total de población entre 1973 y el año 2011. Se debe resaltar que el cantón de Golfito se fue segregando y de sus distritos nacieron dos cantones nuevos: Coto Brus y Corredores. En el caso de la división por sexos, desde 1984 y hasta 2011, se logra una equiparación entre hombres y mujeres, relación que era dispar en años anteriores, esto relacionado con la disminución de la migración y el establecimiento de la población en el cantón.

En lo referido al espacio urbano y rural, la situación en Golfito en 1984 y en el siglo XXI se muestra en la tabla 11. 


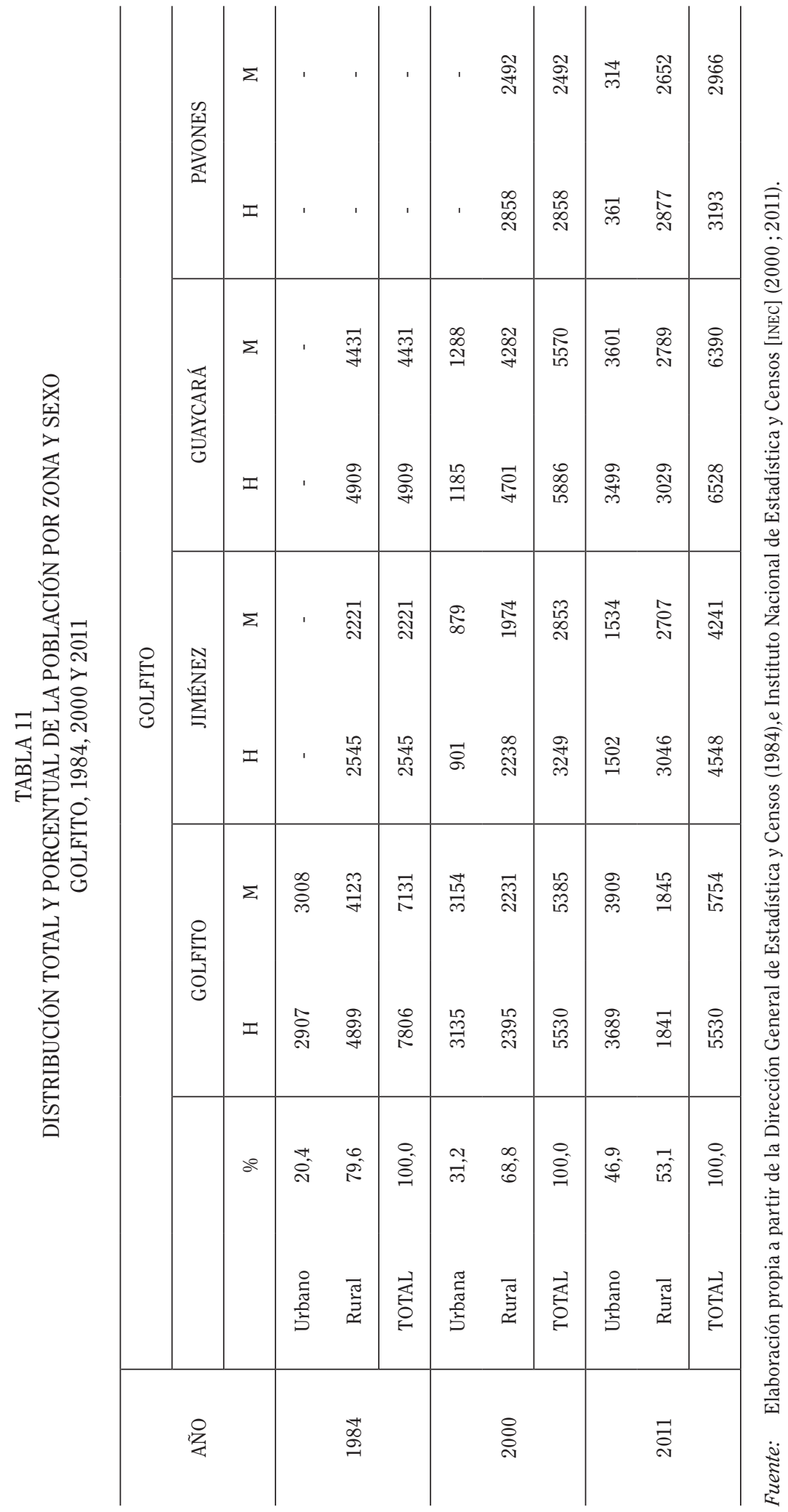


En primera instancia, se observa el aumento porcentual de población urbana y para el año 2000, se registra población urbana en los distritos de Jiménez y Guaycará. Además, en los años 2000 y 2011 se reporta una mayoría de población urbana en el distrito de Golfito, convirtiéndose en el primer distrito en urbanizarse. En el caso de Guaycará, este distrito alcanza una población total mayor que la del distrito central y logra un equilibrio entre su población rural y urbana hacia el año 2011. De esta manera, el Golfito después del finiquito es un cantón más urbano.

En cuanto a la conformación de la población por grupos de edad, en la tabla 12 se muestran los datos para el año 1984.

TABLA 12

DISTRIBUCIÓN TOTAL Y PORCENTUAL DE LA POBLACIÓN POR SEXO Y GRUPOS DE EDAD GOLFITO, 1984

\begin{tabular}{|c|c|c|c|c|c|}
\hline \multirow{2}{*}{ EDAD } & \multicolumn{3}{|c|}{ GOLFITO } & \multicolumn{2}{|c|}{ TOTAL } \\
\hline & GOLFITO & JIMÉNEZ & GUAYCARÁ & & $\%$ \\
\hline Menos de 1 & 379 & 171 & 249 & 799 & 2,7 \\
\hline $1-4$ & 1733 & 608 & 1075 & 3416 & 11,8 \\
\hline $5-19$ & 5836 & 1845 & 3738 & 11419 & 39,3 \\
\hline $20-29$ & 2555 & 794 & 1633 & 4982 & 17,1 \\
\hline $30-39$ & 1665 & 577 & 1039 & 3285 & 11,3 \\
\hline $40-49$ & 1043 & 286 & 661 & 1990 & 6,8 \\
\hline $50-64$ & 1193 & 296 & 625 & 2114 & 7,3 \\
\hline 64 y más & 525 & 189 & 320 & 1038 & 3,6 \\
\hline TOTAL & 14937 & 4766 & 9340 & 29043 & 100,0 \\
\hline
\end{tabular}

Fuente: Elaboración propia a partir de la Dirección General de Estadística y Censos (1984).

La concentración de población se da en el grupo más joven, aunque los datos de este año unifican en un solo grupo las edades entre 5 a 19 años. Al tomar en cuenta que la población mayor a 40 años disminuye en cantidad, se puede afirmar que la juventud característica de este cantón aún se mantenía para este año. Esta misma distribución por edades es observada en los censos del siglo xxi, señalados en la tabla 13. 


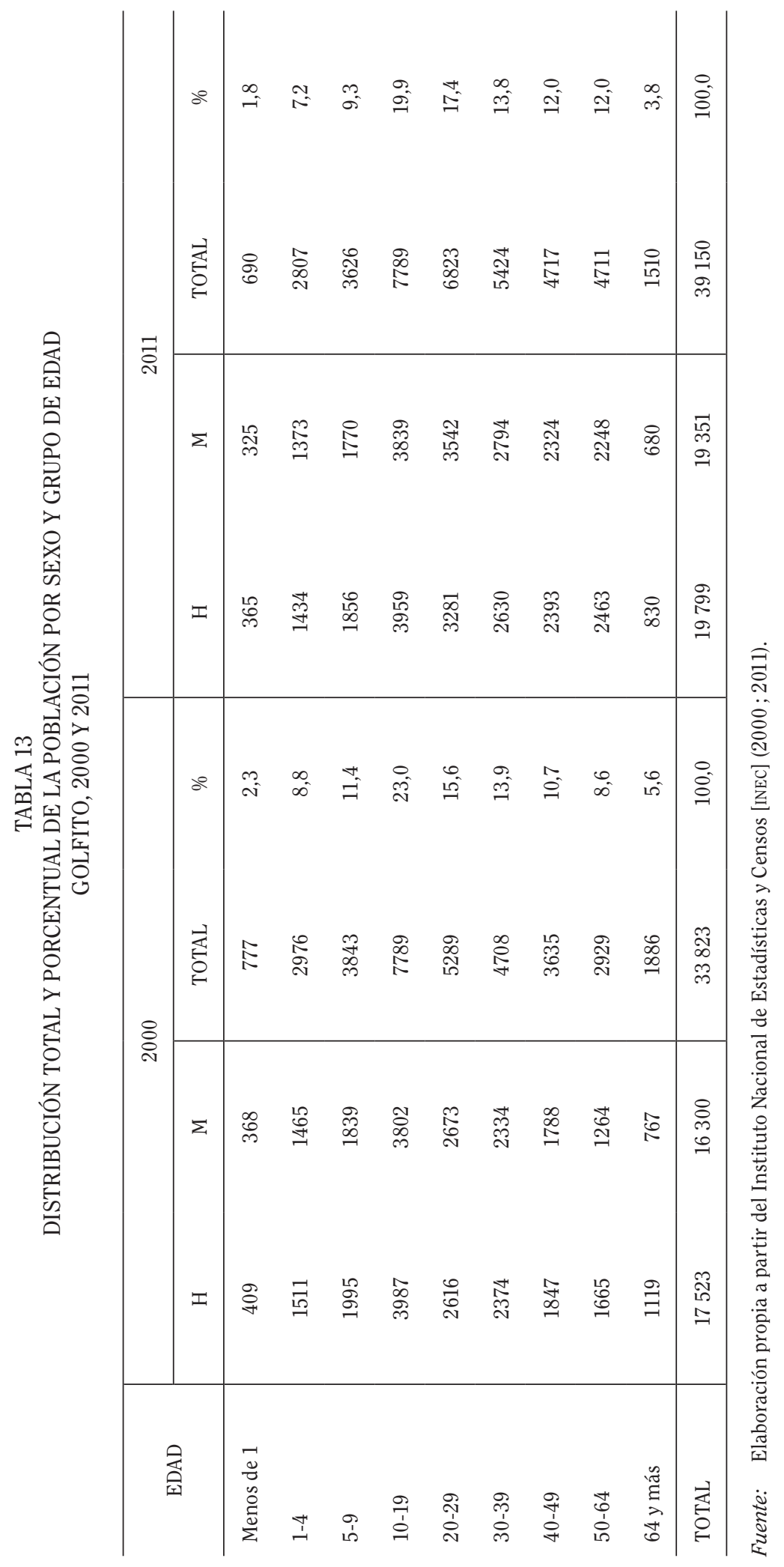


Estos datos sumados a los del año 1984, revelan una disminución de los grupos más jóvenes (5 a 19 años) entre 1984 y 2011. El grupo entre 20-29 años disminuye entre 1984 y el año 2000, para volver a aumentar en 2011. De igual manera, se marca un aumento muy significativo en la población entre 50-64, residentes que envejecieron en este periodo.

En cuanto a movimientos migratorios, en la tabla 14 se tienen los datos acerca del cantón de nacimiento reportado por los habitantes de Golfito en 1984, 2000 y 2011.

TABLA 14

DISTRIBUCIÓN TOTAL Y PORCENTUAL DE LA POBLACIÓN POR LUGAR DE NACIMIENTO GOLFITO, 1984, 2000 Y 2011

\begin{tabular}{|c|c|c|c|c|c|c|c|}
\hline \multirow{3}{*}{ AÑO } & \multirow{3}{*}{$\begin{array}{l}\text { LUGAR DE } \\
\text { NACIMIENTO }\end{array}$} & \multicolumn{4}{|c|}{ SEXO } & \multirow{2}{*}{\multicolumn{2}{|c|}{ TOTALES }} \\
\hline & & \multicolumn{2}{|c|}{ HOMBRES } & \multicolumn{2}{|c|}{ MUJERES } & & \\
\hline & & & $\%$ & & $\%$ & & $\%$ \\
\hline \multirow{4}{*}{1984} & Mismo cantón & - & - & - & - & 14305 & 49,2 \\
\hline & Otro cantón & - & - & - & - & 13347 & 45,9 \\
\hline & Extranjero & - & - & - & - & 1391 & 4,8 \\
\hline & TOTAL & - & - & - & - & 29043 & 100,0 \\
\hline \multirow{4}{*}{2000} & Mismo cantón & 9404 & 27,8 & 8852 & 26,2 & 18256 & 54,0 \\
\hline & Otro cantón & 7334 & 21,7 & 6812 & 20,1 & 14146 & 41,8 \\
\hline & Extranjero & 785 & 2,3 & 636 & 1,9 & 1421 & 4,2 \\
\hline & TOTAL & 17523 & 51,8 & 16300 & 48,2 & 33823 & 100,0 \\
\hline \multirow{4}{*}{2011} & Mismo cantón & 11643 & 29,7 & 11361 & 29,0 & 23004 & 58,7 \\
\hline & Otro cantón & 7392 & 18,9 & 7307 & 18,7 & 14699 & 37,5 \\
\hline & Extranjero & 764 & 1,9 & 683 & 1,7 & 1477 & 3,8 \\
\hline & TOTAL & 19799 & 50,6 & 19351 & 49,4 & 39150 & 100,0 \\
\hline
\end{tabular}

Fuente: Elaboración propia a partir del Instituto Nacional de Estadísticas y Censos [INEC] (2000; 2011).

Se destaca la disminución porcentual de la población nacida en el extranjero, un componente que fue de gran importancia en los años de producción bananera. Así, los extranjeros pasan de un $4,8 \%$ en 1984 a un 3,8\% en 2011. Además, se reporta un aumento de los residentes que nacieron en el mismo Golfito, con casi 10 puntos porcentuales en 27 años. A nivel real, entre 2000 y 2011, se observan más o menos las mismas 14 mil personas entre los nacidos en otro cantón, con lo cual fueron pocas las que decidieron llegar de otro cantón a residir en Golfito.

Este dato se observa con más claridad en la tabla 15 , si se realiza una comparación del comportamiento migratorio del cantón en los años censados. 
TABLA 15

INMIGRACIÓN INTERNA, EMIGRACIÓN INTERNA, SALDO MIGRATORIO Y TASA NETA DE MIGRACIÓN GOLFITO, 1984, 2000 Y 2011

\begin{tabular}{l|c|cc|c|cc|c}
\hline & 1984 & \multicolumn{3}{|c|}{2000} & \multicolumn{3}{c}{2011} \\
\cline { 2 - 8 } & & $\mathrm{H}$ & $\mathrm{M}$ & TOTAL & $\mathrm{H}$ & $\mathrm{M}$ & TOTAL \\
\hline Población 5 años y más & 24828 & 15603 & 14467 & 30070 & 18000 & 17653 & 35653 \\
Inmigración interna & 4420 & 1735 & 1658 & 3393 & 2038 & 2022 & 4060 \\
Emigración interna & 4396 & 2318 & 2182 & 4500 & 1642 & 1733 & 3375 \\
Saldo migratorio & 24 & -583 & -524 & -1107 & 396 & 289 & 685 \\
Tasa neta migración & 0,1 & $-7,4$ & $-7,2$ & $-7,3$ & 4,5 & 3,3 & 3,9 \\
\hline
\end{tabular}

Fuente: Elaboración propia a partir de Gonzáles y Varela (1987), e Instituto Nacional de Estadísticas y Censos [INEc] $(2000 ; 2011)$.

La tabla 15 muestra como en el año de 1984 se reportó un saldo migratorio apenas positivo, después del finiquito para el año 2000 se evidencia que Golfito es un cantón que expulsa personas, pues la diferencia de los que llegaron con respecto a los que se fueron es negativa. En 2011, se logra una recuperación importante y el saldo vuelve a ser positivo. De esta manera, este centro histórico de inmigración que logró atraer una enorme cantidad de personas en la segunda mitad del siglo xx, con el abandono de la actividad bananera se convirtió en una zona migratoria apenas estable en el siglo xxI.

A nivel étnico, en el censo del 2011 se caracteriza a la población golfiteña según se muestra en la tabla 16.

TABLA 16

DISTRIBUCIÓN PORCENTUAL DE LA POBLACIÓN POR DISTRITO Y GRUPO ÉTNICO GOLFITO, 2011

\begin{tabular}{l|cccc|c}
\hline \multirow{2}{*}{ GRUPO ÉTNICO } & \multicolumn{4}{|c|}{ GOLFITO } & \multirow{2}{*}{ TOTAL } \\
\cline { 2 - 4 } & GOLFITO & JIMÉNEZ & GUAYCARÁ & PAVONES & \\
\hline Indígena & 1,6 & 2,4 & 2,1 & 19,7 & 4,8 \\
Afrodescendientes & 1,0 & 1,6 & 0,7 & 0,3 & 0,9 \\
Mulata & 10,0 & 12,1 & 9,4 & 4,3 & 9,4 \\
China & 0,2 & 0,1 & 0,1 & 0,0 & 0,2 \\
Mestiza o blanca & 80,4 & 71,5 & 84,1 & 71,2 & 78,1 \\
\hline
\end{tabular}

Fuente: Elaboración propia a partir del Instituto Nacional de Estadísticas y Censos [INEc] (2011).

La producción bananera en Golfito no dinamizó la composición étnica de la población a un nivel significativo aún en la actualidad, a diferencia de lo ocurrido en Limón.
Así, la población afrodescendiente es minoritaria, al tomar en cuenta la directriz de evitar este tipo de migración en el nuevo enclave. Igualmente, ocurre con la población china, la cual 
no tiene un peso significativo. Aunque existe presencia indígena en todo el cantón, esta se concentra principalmente en el distrito de Pavones. Las personas autodenominadas mulatas se concentran principalmente en Jiménez.
En lo referente a la composición educativa de esta población, en la tabla 17 se observan los datos referidos al nivel de instrucción, asistencia a centros educativos formales y alfabetización según el Censo de 1984.

TABLA 17

DISTRIBUCIÓN TOTAL DE LA POBLACIÓN SEGÚN NIVEL DE INSTRUCCIÓN, ASISTENCIA A UN CENTRO DE EDUCACIÓN FORMAL Y ALFABETIZACIÓN GOLFITO, 1984

\begin{tabular}{|c|c|c|c|c|c|}
\hline \multirow{2}{*}{ NIVEL DE INSTRUCCIÓN } & \multicolumn{3}{|c|}{ GOLFITO } & \multicolumn{2}{|c|}{ TOTAL } \\
\hline & GOLFITO & JIMÉNEZ & GUAYCARÁ & & $\%$ \\
\hline Ninguno & 2849 & 958 & 1654 & 5461 & 22,0 \\
\hline Primaria & 7709 & 2739 & 5067 & 15515 & 62,5 \\
\hline Secundaria & 2028 & 265 & 1183 & 3476 & 14,0 \\
\hline Universitaria & 239 & 25 & 112 & 376 & 1,5 \\
\hline Asistencia & & & & & \\
\hline Asiste & 3618 & 786 & 2240 & 6644 & 26,8 \\
\hline No asiste & 9207 & 3201 & 5776 & 18184 & 73,2 \\
\hline TOTAL & 12825 & 3987 & 8016 & 24828 & 100,0 \\
\hline ALFABETIZACIÓN & GOLFITO & JIMÉNEZ & GUAYCARÁ & & $\%$ \\
\hline Alfabetizados & 9150 & 2731 & 5855 & 17736 & 85,6 \\
\hline Analfabetas & 1598 & 581 & 800 & 2979 & 14,4 \\
\hline TOTAL & 10748 & 3312 & 6655 & 20715 & 100,0 \\
\hline
\end{tabular}

Fuente: Elaboración propia a partir de la Dirección General de Estadística y Censos (1984).

Estos datos de 1984 pueden ser comparados con los obtenidos en los censos para los años 2000 y 2011, señalados en las tablas 18 y 19. 


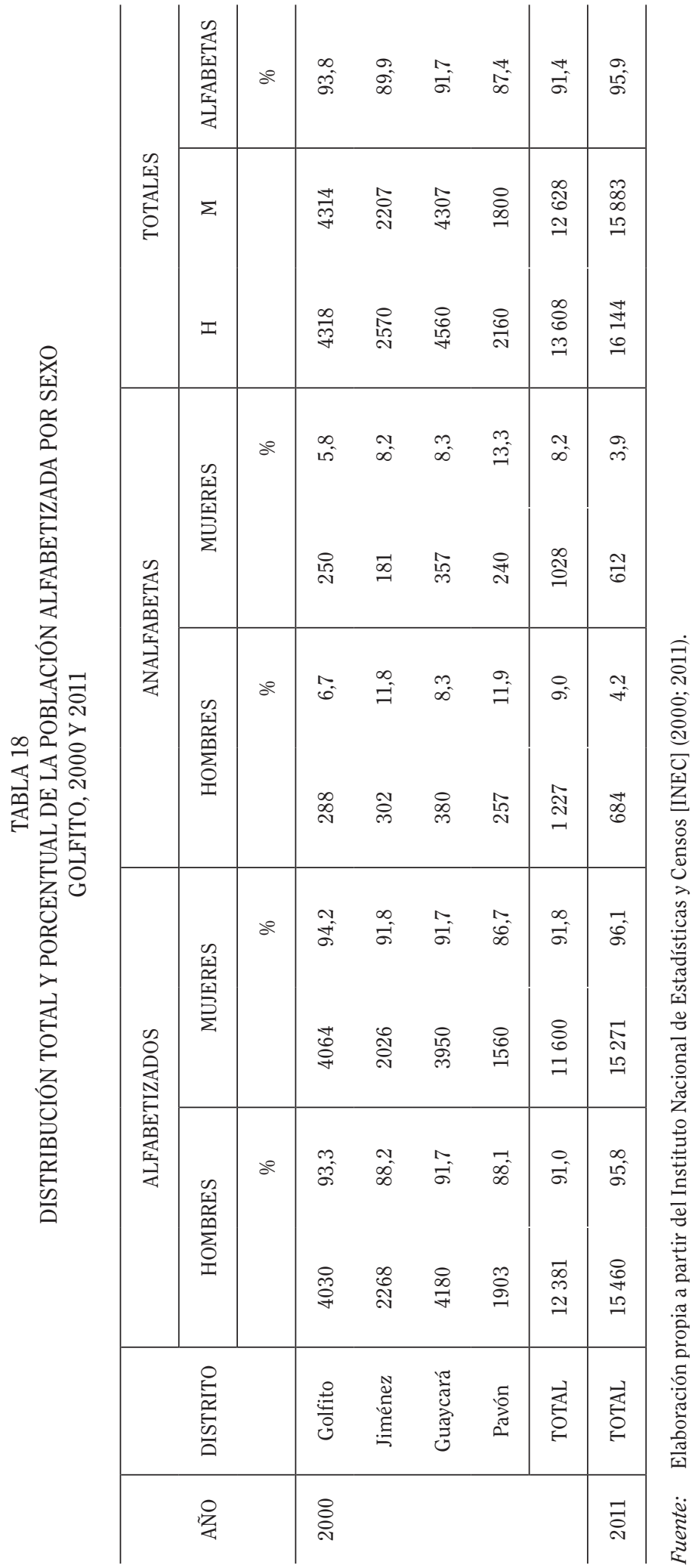




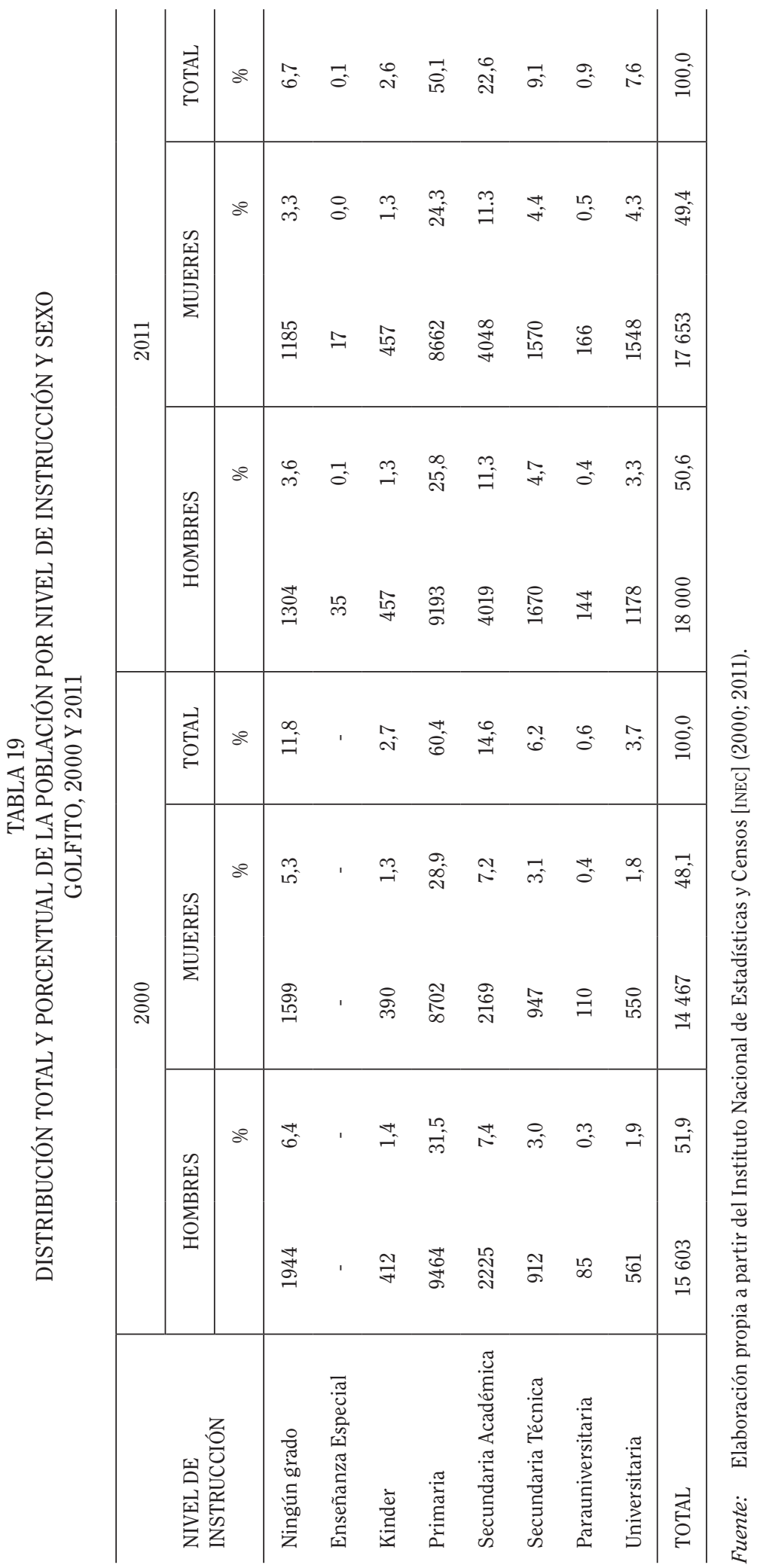

(C) (7) \&) Rev. Ciencias Sociales Universidad de Costa Rica, 167: 135-160 / 2020 (I). (ISSN: 0482-5276) 
Una comparación de estos datos indica el avance en la alfabetización ocurrido en esta zona desde 1984 y hasta 2011, cuando la población que sabe leer y escribir pasa del 85,6\% al 95,9\%. En 1984, Jiménez es el distrito menos alfabetizado; en el año 2000, ya es el nuevo distrito de Pavones el que tiene esta condición, además, el que tienen mayor población indígena. En el siglo XxI, la diferencia entre sexos no es significativa y existe una leve ventaja de hombres analfabetos con respecto a las mujeres.

Estas cifras muestran que el abandono de la Compañía y la posterior crisis económica en la que se sumergió Golfito, no afectó sus cifras de alfabetización $y$, por el contrario, estas avanzaron, siendo la educación primaria un servicio cubierto por el Estado, lo que permitió a los niños y niñas golfiteñas instruirse aun después del finiquito.

El grado de instrucción es el que refleja los cambios más importantes, pues existen grados como Educación Secundaria y Universitaria que ganan porcentajes en cuanto avanza el tiempo. De esta manera, los descensos en Primaria registrados de 1984 al 2000 y de este año al 2011, se explican por el aumento de los tipos de educación post primarios. Así, el nivel de Secundaria desde 1984 al 2000 ha aumentado en 7 puntos porcentuales, $y$ en al año 2011, es más del doble de lo que fue 27 años atrás. Cabe destacar que la modalidad Académica es la más expandida de este grado de educación. En cuanto a la educación universitaria, esta reporta un aumento del doble entre 1984 y el año 2000, y nuevamente del doble en 2011. A nivel de sexos, existe una relación muy pareja entre hombres y mujeres con respecto a la educación secundaria, pero en 2011, el porcentaje de mujeres universitarias es mayor.

La causa del cese del cultivo de banano responde a que este producto dejó de ser rentable por una serie de factores, tantos nacionales como internacionales (Abarca, julio-diciembre, 2015). Entre los factores nacionales destaca el alto costo para poder mantener la producción. En los factores internacionales se aprecian la sobreoferta de la fruta a partir de 1980 y la estrategia de diversificación productiva de la United Brand, socio mayoritario de la Compañía. La participación de Costa Rica en la producción mundial bajó y la cuota del país en la Unión de Países Exportadores de Banano descendió de 36,7\% en 1974 a 26,3\% en 1983 (Abarca, julio-diciembre, 2015). La disminución en el cultivo de banano significó un aumento en el cultivo de palma aceitera. De esta manera, en 1979, del total de hectáreas sembradas por la Compañía en el Pacífico Sur, un $59 \%$ estaban cultivadas de palma, frente a un 29\% de banano (Royo, 2004). Posteriormente, entre 1979 y 1989, las hectáreas cultivadas de palma se duplicaron, alcanzando las 22970 (Abarca, julio-diciembre, 2015).

La salida de la Compañía implicó que se abandonara repentinamente un modelo productivo sin tener a la vista otro para sustituirlo. Lo anterior se observa en las tablas 20 y 21, con una comparación entre las actividades económicas registradas en los censos para el año de 1984 (justo antes del finiquito) y el siglo XXI (décadas después de la salida de la Compañía Bananera). 
TABLA 20

DISTRIBUCIÓN TOTAL Y PORCENTUAL DE LOS OFICIOS DE LA POBLACIÓN ECONÓMICAMENTE ACTIVA GOLFITO, 1984

\begin{tabular}{l|c|c}
\hline OFICIOS & & $\%$ \\
\hline Profesionales $y$ técnicos & 481 & 5,6 \\
Administradores y gerentes & 112 & 1,3 \\
Empleados del estado y privados & 301 & 3,5 \\
Comerciantes y vendedores & 422 & 4,9 \\
Agricultura, ganadería y pesca & 4529 & 52,4 \\
Medios de transporte & 170 & 2,0 \\
Artesanos e industria I & 629 & 7,3 \\
Artesanos e industria II & 456 & 5,3 \\
Estibador, carga y bodegueros & 215 & 2,5 \\
Servicios & 734 & 8,5 \\
No identificada & 592 & 6,8 \\
\hline TOTAL & 8641 & 100,0 \\
\hline
\end{tabular}

Fuente: $\quad$ Elaboración propia a partir de la Dirección General de Estadística y Censos (1984).

TABLA 21

DISTRIBUCIÓN TOTAL Y PORCENTUAL DE LOS OFICIOS DE LA POBLACIÓN ECONÓMICAMENTE ACTIVA GOLFITO, 2000 Y 2011

\begin{tabular}{|c|c|c|c|c|}
\hline \multirow{2}{*}{ OFICIOS } & \multicolumn{2}{|c|}{2000} & \multicolumn{2}{|c|}{2011} \\
\hline & & $\%$ & & $\%$ \\
\hline Dirección y Administración pública y privada & 96 & 1,0 & 117 & 0,9 \\
\hline Profesionales y científicos & 549 & 5,5 & 951 & 7,3 \\
\hline Técnico y profesional medio & 771 & 7,7 & 838 & 6,4 \\
\hline Apoyo administrativo & 655 & 6,6 & 713 & 5,4 \\
\hline Ventas & 1826 & 18,3 & 3028 & 23,1 \\
\hline Agricultura, ganadería, pesca & 1329 & 13,3 & 1093 & 8,3 \\
\hline Artesanos & 847 & 8,5 & 1212 & 9,3 \\
\hline Operarios & 587 & 5,9 & 896 & 6.8 \\
\hline No calificados & 3324 & 33,3 & 4231 & 32,3 \\
\hline TOTAL & 9984 & 100,0 & 13079 & 100,0 \\
\hline
\end{tabular}

Fuente: Elaboración propia a partir del Instituto Nacional de Estadísticas y Censos [INEc] (2000; 2011). 
Se observa como disminuye considerablemente la actividad agrícola desde 1984 hasta el 2011, pasando de ser la actividad más desempeñada por la población ocupada, a ser el oficio de apenas un $8,3 \%$.

Dentro de la estrategia del Gobierno para dinamizar la economía en el sur del país, se dio la creación del Depósito Libre Comercial de Golfito (DLCG), una zona de venta de artículos libres de impuestos. La Ley nro. 7012 de 1985 establece este centro comercial con el objetivo explícito de reactivar la economía y la atracción turística de las zonas afectadas por el abandono de la actividad bananera (art. 1).

Aunque la experiencia del DLCG se conoce poco, su funcionamiento puede explicar en parte el aumento del sector ventas en ambos años censales. Además de intensificar el sector servicios en hospedajes y restaurantes, al obligar a los compradores a quedarse al menos una noche en la zona (Rojas, 1995). Aún así, su impacto parece ser limitado si se toma en cuenta que la mayoría de la mano de obra productiva en el siglo Xxi se encuentra en el sector de la informalidad, pues en los años 2000 y 2011, los empleos no calificados ocuparon respectivamente al 33,3\% y al 32,3\% de los trabajadores golfiteños.

\section{CONCLUSIÓN}

La configuración del espacio geográfico que constituye el actual cantón de Golfito tiene al menos tres periodos claramente definidos. En el primero, se observa la dinámica alrededor del Golfo Dulce, desde mediados del siglo XIX hasta la llegada de la Compañía Bananera, la apertura del muelle en 1941 y la fundación del cantón en 1949. En dicho periodo se observa la integración de este espacio bajo la administración del gran cantón de Osa, la lógica de la frontera con Chiriquí y los esfuerzos de las autoridades gubernamentales $y$ vecinos para integrar esta región a la dinámica social y económica nacional.

En un segundo periodo, desde 1949 hasta 1984, se observa como esta dinámica es alterada completamente con la instalación y consolidación de la producción bananera. Este modelo transformaría la región del Golfo Dulce, influenciando la composición poblacional del cantón, con una atracción de mano de obra migrante y marcadamente masculina, proveniente de cantones de las provincias de Puntarenas, San José y Guanacaste, así como de otros países centroamericanos como Panamá y Nicaragua.

Finalmente, en 1984 se inaugura un nuevo periodo con el cambio de la matriz productiva de la Compañía al migrar del banano a la palma, el finiquito del contrato de 1938 y el cese de operaciones de cultivo y exportación de la fruta. En este nuevo periodo, Golfito dejó de ser un foco de atracción de población y contrario a eso, expulsó a muchos de sus habitantes. Además, el abandono de la producción bananera trajo como consecuencia que muchos trabajadores dedicados a labores agrícolas no pudieran colocarse en otro sector de la economía, impulsando así el sector de la informalidad.

\section{REFERENCIAS}

Abarca, C. (2005). Obreros de la Yunai.

Abarca, G. (julio-diciembre, 2015). Contexto histórico del cese del enclave bananero en la Zona Sur de Costa Rica (19721985). Revista Universidad en Diálogo, 5(2), 187-205.

Arias, D. (agosto de 2007-febrero de 2008). Aproximación al estudio del cantón de Osa (1914-1990). Diálogos, 8(2).

Barrantes, C. (2005). Historia de la región del Golfo Dulce. En F. Bolaños y J. Lobos. (Eds.), Historia Natural de Golfito. InBio.

Bartels, J. y Araya, A. (2011). El desarrollo de la agricultura en la Región Pacífico Sur de Costa Rica (1909-1955). En J.J., Marín. (Ed.), El sur-sur. Trayectorias y perspectivas de una región en proceso de formación. 1821-2010. Sociedad Editora Alquimia.

Boza, A. (2014). La frontera indígena de la Gran Talamanca 1840-1930. EDUPUC.

Consejo Superior Universitario Centroamericano [CsUCA]. (1978). Estructuras demográficas y migraciones internas en Centroamérica. EDUCA.

Contreras, F. (1974). Evolución histórica del enclave bananero en Costa Rica [Tesis de grado, Licenciatura en Historia]. Universidad de Costa Rica. 
Dirección General de Estadística. (1892). Censo de la República de Costa Rica 1892. http://ccp.ucr.ac.cr/bvp/documentos.htm

Dirección General de Estadística y Censos. (1927). Censo de la República de Costa Rica 1927. http://ccp.ucr.ac.cr/bvp/documentos.htm

Dirección General de Estadística y Censos. (1950). Censo de la República de Costa Rica 1950. http://ccp.ucr.ac.cr/bvp/documentos.htm

Dirección General de Estadística y Censos. (1963). Censo de la República de Costa Rica 1963. http://ccp.ucr.ac.cr/bvp/documentos.htm

Dirección General de Estadística y Censos. (1973). Censo de la República de Costa Rica 1973. http://ccp.ucr.ac.cr/bvp/documentos.htm

Dirección General de Estadística y Censos. (1984). Censo de la República de Costa Rica 1984. http://ccp.ucr.ac.cr/bvp/documentos.htm

Gonzáles, H. y Varela, J. (1987). Movimientos migratorios en Costa Rica. Censo de la Población 1984. Revista de Historia, 7, 7-8.

Hernández, H. (1985). Costa Rica: evolución territorial y principales censos de población 1502-1984. EUNED.
Instituto de Investigaciones Económicas [IIE]. (1974). La Población de Costa Rica. Editorial de la Universidad de Costa Rica. Instituto Nacional de Estadística y Censos [INEC]. (2000). Censo de la República de Costa Rica 2000. http://www.inec.go.cr/ censos/censos-2000

Instituto Nacional de Estadística y Censos [INEc]. (2011). Censo de la República de Costa Rica 2011. Recuperado de http:// www.inec.go.cr/censos/censos-2011

Jones, C. y Morrison, P. (1952). Evolution of banana industry in Costa Rica. Economic Geography, 28(1).

República de Costa Rica. (1864). Censo de la República de Costa Rica 1864. http://ccp. ucr.ac.cr/bvp/documentos.htm

Rojas, R. (1995). Evaluación del Depósito Libre Comercial de Golfito [Tesis de grado, Licenciatura en Administración Pública]. Universidad de Costa Rica.

Royo, A. (2004). La ocupación del Pacífico Sur por parte de la Compañía Bananera. Diálogos, 4(2).

Fecha de ingreso: 07/12/2018 Fecha de aprobación: 09/10/2019 